Community paediatrics

\section{Community paediatrics in crisis}

\author{
M Mather
}

\section{Primary care trusts are advertising; is anyone listening?}

T the armchair pundit, advertisements are always a useful antidote to the soporific parts of the scientific journal or television programme. Brief, dramatic, witty, or sentimental, they painlessly separate us from our hard earned cash. Advertising for new consultants is less sophisticated, subtle, or humorous, remaining largely reliant on "glorious countryside and local good schools" which are apparently endemic in all corners of the British Isles. However, the study of consultant advertisements can be illuminating and should be introduced to all junior doctors as a special study module, since they give invaluable information about how commissioners propose to invest scarce health resources on local children. Have paediatricians read the subliminal messages?

Every year, over 300 substantive consultant posts in paediatrics are advertised in the British Medical Journal. For the past five years, approximately $40 \%$ have been for community, neurodisabilty, or ambulatory posts. No other paediatric specialty gets remotely close to this figure. In second and third place respectively were acute general paediatrics and neonatology. The number of advertised posts in every other paediatric specialty rarely achieves double figures. British children seem to need generalists working outside hospital boundaries, not "ologists" working in tertiary centres.

Another useful source of information about British children is the statistics regularly produced by the Department of Health. ${ }^{1}$ There are 11.7 million dependent children in England and Wales; a number greater than the populations of countries like Sweden, Belgium, Portugal, or Greece. British children are disproportionately present in low income households, 2.6 million live in lone parent families, and 2.7 million live in low income households.

Of the 376000 children "in need", $13 \%$ have a disability. Local authorities look after 59700 children. There are 12600 unaccompanied asylum seeking children. ${ }^{2}$ Every year, 3600 children are placed for adoption, 27500 children are placed on child protection registers, ${ }^{1}$ and 90000 teenagers become pregnant. ${ }^{2}$
Of the 320000 disabled children, 110000 are severely disabled; 1.7 million children pupils have special educational needs, including 250000 children with statements of special educational needs. ${ }^{2}$

At least 250000 children live with a parent who has a serious drug problem. ${ }^{3}$ Ten per cent of children aged 11-15 are regular smokers, $24 \%$ have tried alcohol, $12 \%$ cannabis, $4 \%$ stimulants, $1 \%$ opiates, and 35\% had been offered drugs. ${ }^{4}$ The prevalence rate for problematic psychological conditions in childhood is $20 \%$, increasing to $68 \%$ in deprived areas. ${ }^{5}$

Non-acute, non-hospital work is growing rapidly. Increasing numbers of low birth weight babies survive. There are more children with disability, more affected by abuse and neglect, more behaviour problems, more school exclusions, and a growing public demand from parents desperate to see "a specialist".

\section{WHERE ARE THE DOCTORS WHO WILL CARE FOR CHILDREN OUTSIDE HOSPITALS?}

If recruits are the life blood of a service, then community paediatric services are terminally ill. In 2002, the British Association of community Child Health (BACCH) tried to identify the number of specialist registrars in training for community posts. Of approximately 1000 national training numbers (NTNs) in England and Wales, only 88 were identified as training in community. All these doctors were written to twice to try to identity how many actually intended to become community paediatricians. Only 38 specialist registrars responded with firm intentions of pursuing a community career. ${ }^{6}$

\section{WHY IS COMMUNITY WORK SO UNPOPULAR?}

Community paediatrics is in crisis for a number of reasons. There is widespread disparagement of work still considered to be something of a "soft" option. "Married women earning pin money in the community" was a recent description by a senior colleague. Academic and tertiary services are focused largely on organ and system disease and insufficiently interested in the major child health issues affecting UK children.
Professional kudos is still reserved for paediatricians treating rare diseases in small numbers of children.

Community activity is rarely recognised in official statistics or waiting lists. Community services rarely have sophisticated monitoring systems, waiting list managers, or even accurate referral data. It is often forgotten that in addition to general practitioners; parents, teachers, therapists, and social workers refer children directly to community paediatricians. This uncounted work, which bypasses the commissioners, counts heavily against community services in an era dominated by resources attached to waiting lists and targets.

Outside child development centres, facilities in the community are generally poor. Children are often seen without nurses, background information, or equipment, in rooms without toys or spaces to play. Problems providing high quality secondary and tertiary community services are often exacerbated by difficulties in accessing hospital facilities, test results, or medical records.

The skills needed to provide good care outside a protected hospital environment are not taught at either medical school or in postgraduate training. The unexpected complexity of the work, particularly when a doctor is unsupported, can lead to isolation and vulnerability. A specialist registrar with outstanding qualifications and clinical skills described running a clinic on a deprived estate as the "most terrifying thing" she had ever done.

\section{THE SOFT OPTION IS NO LONGER SOFT}

The first paediatricians were community doctors employed in schools and infant welfare clinics run by local authorities, at the end of the nineteenth century. Adult physicians on adult wards saw acutely ill children. Acute paediatrics as a specialty began with the formation of the British Paediatric Association in 1928, but only really became established after the Second World War.

In 1989, when the first edition of Health for all children ${ }^{7}$ was published, our team of 16 community doctors saw every child at 6 weeks, 8 months, 24 months, 39 months, 5 years, 7 years, and 11 years. The routine examination of 14 year olds had just stopped despite protests from parents, teachers, and school nurses. Three editions and 14 years later, paediatric work in the community work has changed beyond recognition. The old, defect detecting, universal, medical model of child health no longer exists. Community paediatrics is now secondary or even tertiary level work that is both consultant led and consultant delivered. 
This change has accelerated as the political climate has changed. The government committed to reducing inequalities proposes substantial investments in early years, child mental health, and education. The National Service Framework for Children (NSF) and Children's' Trusts are on the horizon. Beleaguered, shrinking community services are expected to deliver the bulk of these initiatives. Most consultants now have in-trays several inches high, full of long awaited government directives but no staff to put them into place.

Medical support to social services has increased with the introduction of designated and named doctors for child protection and for looked after children. The statutory Framework for the assessment of children in need ${ }^{8}$ requires the holistic medical assessment of children with complex social problems. Every district needs a senior doctor responsible for educational medicine and the statutory statementing process for special educational needs. There are increased numbers of health assessments on looked after children and new targets in adoption.

Vaccination rates, especially MMR uptake, are dependent on experienced immunisation coordinators working with primary care teams. New national campaigns like meningitis $\mathrm{C}$ and Hib have been implemented, and new vaccinations and new screening programmes are waiting to come on stream.

Every primary care trust must offer a full range of services for children with disability from diagnosis to school leaving age. Mental health resources are scare. In their absence, community paediatricians largely manage the complex emotional and behavioural problems of disabled children, together with attention deficit hyperactivity disorder and the autistic spectrum disorders. Audiology, enuresis, and encopresis clinics, small but invaluable community services, have serious recruitment problems The work is fascinating, challenging, never dull, and can only be delivered by experienced doctors willing to work long hours in a complex multidisciplinary and multi-agency environment.

\section{THE FUTURE}

In 1963, another doctor, Dr Beeching looked at rail services in the United Kingdom. Rarely used branch lines were ruthlessly pruned and only large, cost effective, busy main lines survived. Where branch lines survived, communities flourished; where they no longer existed, communities were condemned to progressive isolation as petrol became more expensive. Forty years later, after global warming, spiralling oil prices, and the development of energy, efficient trains, this short-sighted rationalisation is seen in a new light. Without the basic infrastructure a holistic twenty first century transport policy is difficult to develop.

Sadly, British community child health has undergone a "Dr Beeching" rationalisation. The complex network of community services, the branch lines that would allow new service development, have disappeared and will not be easy to replace. Successive generations of managers saw little point in retaining services not on a priority "must do" list that were perceived as unimportant or could be undertaken in primary care.

Our team of 16 doctors is now reduced to seven and our specialist registrar was withdrawn. Six doctors will retire within five years. We retain our enthusiasm and commitment and continue a campaign of hopeless advertising, but there are vacant community consultant posts in every surrounding local district. Appointment committees mainly interview existing consultants, thus transferring vacancies to other districts.

A recent BACCH document ${ }^{9}$ estimates that the average district population of 250 000-300 000 requires a minimum of 4.6 whole time equivalent (wte) consultant community paediatricians to provide good enough care and fulfil all the statutory obligations on the service. Disadvantaged populations with higher rates of disability and social need will require more than this minimum. In addition to consultants, all community child health services are still heavily dependent on non-consultant, career grade paediatricians, and workforce estimates also show a rapid decline in the numbers of these doctors. As career grade numbers decline, services will need to be maintained by the creation of new consultant or associate specialist posts, and there are virtually no doctors in training. Urgent action is required.

The distinction between the acute and community paediatrician needs to disappear. Both are consultants delivering secondary care; both need access to facilities that will help them to fulfil their roles. The future must also see hospital paediatricians spending significantly more time in the community.

Training in community child health needs to be systematically increased. Enthusiastic well resourced departments have a much greater success rate in attracting scarce specialist registrars. All undergraduates need basic training in disability, child protection, child mental health, and the impact of deprivation. The time devoted to community training for general practitioner registrars, senior house officers, and specia- list registrars needs to increase considerably. Doctors in training need more than knowledge. The competency to manage a problem is gained not in the minimum six month community placement currently recommended but by years of experience. Change must therefore occur while there are sufficient numbers of enthusiastic community paediatricians with the time to teach, mentor, and support young doctors while they develop their skills.

Specialist registrar "ologists" must know how to access educational and social provision for their patients and families. Children will survive and go to school for many years after the initial investigation and diagnosis. A child's prognosis and quality of life depends as much on social support for their parents and educational provision as on diagnostic acumen or surgical skill.

Most radical of all, perhaps the time has come for national training numbers to be allocated on the basis of what British children need rather than the career aspirations of paediatricians. We are after all spending public money. Practically this would mean at least $40 \%$ of NTNs being reserved for paediatricians intending to work largely in the community.

The beginning of the NSF for children states clearly that hospital care is no more important to children than other health services. Indeed for most children, most of the time, hospitals are thankfully irrelevant. Hospitals and presumably paediatricians cannot continue to stand apart from the rest of the health and social care system. ${ }^{10}$ Our children are much too valuable.

Arch Dis Child 2004;89:697-699. doi: 10.1136/adc.2003.038950

Correspondence to: Dr M Mather, Consultant Community Paediatrician, Bexley Primary Care Trust, London, UK; mary.mather@bexley.nhs.uk

\section{REFERENCES}

1 National Statistics, 1 Drummond Gate, London SWIV 2QQ, www.statistics.gov.uk.

2 Department of Health. Getting the right start; National Service Framework for Children, Emerging findings. London: HMSO, 2003.

3 Home Office. Hidden harm. Responding to the needs of children of problem drug users. A report of an inquiry by the Advisory Council on the Misuse of Drugs. London: HMSO, 2003.

4 Department of Health. Smoking, drinking and drug use among young people in England in 2000. National statistics. London: HMSO, 2001

5 Hall DMB, Elliman D. Health for all children, 4th edn. Oxford: Oxford University Press, 2003

6 Dr Julia Hale, BACCH Trainee Representative and RCPCH, Community Child Health CSAC Trainee Representative. Personal communication, BACCH News, RCPCH, London, 2002.

7 Hall DMB, ed. Health for all children. A programme for child health surveillance. Oxford: Oxford University Press, 1989 
8 Department of Health, Department for Education and Employment, Home Office. Framework for the assessment of children in need and their families. London: HMSO, 2000.
9 Bhrolchain C. Community Paediatric Workforce requirements to meet the needs of children in the 21 st century. London: BACCH, 2002.
10 Department of Health. Getting the right start; National Service Framework for Children. Standards for Hospital Services. London: HMSO, 2003.
Rickets

\section{Is nutritional rickets returning?}

\section{J Allgrove}

\section{See original article by Ladhani et al (pp 781-4)}

M ineralisation of osteoid tissue of bone is dependent on a suitable supply of mineral, both calcium and phosphate, to that tissue. Failure to provide sufficient mineral results in osteomalacia which, in growing bone with its attendant growth plates and unfused epiphyses, is manifest as rickets. Although vitamin D deficiency is not the only cause of rickets (nutritional calcium deficiency has also recently been proposed as an important factor ${ }^{1}$ ), it has historically been a major cause of morbidity. ${ }^{2}$

Vitamin D is mainly derived from the action of sunlight on 7-dehydrocholesterol in the skin, and vitamin D deficiency is more likely to occur in individuals with darker skins or in those whose skin is extensively covered. Vitamin D is converted via two enzymatic reactions to the active metabolite, 1,25-dihydroxyvitamin D $\quad(1,25-$ $\left.(\mathrm{OH})_{2} \mathrm{D}\right)$, whose principal actions are to stimulate absorption of calcium by the gut and promote mineralisation of bone. Failure to do so adequately may therefore result in osteomalacia and rickets; it also limits peak bone mass ${ }^{4}$ and contributes to involutional osteoporosis. ${ }^{5}$ Vitamin D deficiency in pregnant mothers also limits fetal growth. ${ }^{6}$ In addition, vitamin $\mathrm{D}$ may have an important part to play in preventing other diseases such as hypertension, various cancers, and type 1 diabetes. ${ }^{5}$

Rickets is not a new disease. It was first described by an English physician, Dr Daniel Whistler, in 1645, although it is known to have existed well before that. ${ }^{7}$ It has long been recognised that lack of exposure to adequate amounts of sunlight was a major cause of vitamin D deficiency rickets which, following the industrial revolution, became a significant cause of morbidity especially in the urbanised cities of the north of England and Scotland. As the causes of so called "nutritional" rickets became better understood, and particularly following the second world war when the priva- tions of food rationing necessitated a closer examination of minimal nutritional requirements, nutritional rickets virtually disappeared in the UK, particularly with the introduction of vitamin D supplementation in the form of cod or halibut liver oil and the fortification of foods.

Rickets is a relatively rare condition in western societies and, when it presents, is often associated with some form of metabolic disturbance of vitamin D metabolism, which may be primary (for example, vitamin D dependent rickets type 1 , an inborn error of metabolism of vitamin D; or vitamin D dependent rickets type 2, end organ resistance to the action of vitamin $\mathrm{D}$ ) or secondary (for example, associated with liver or kidney disease), or a defect in renal tubular function (for example, hypophosphataemic vitamin $\mathrm{D}$ resistance rickets). ${ }^{8}$ However, over the past few years several reports have appeared which have suggested that nutritional rickets is reappearing in the UK, ${ }^{9-11}$ Europe, ${ }^{12-20}$ and North America ${ }^{21-26}$ in a variety of ethnic groups. Other reports have suggested, perhaps surprisingly, that rickets is also prevalent in sunnier climes, ${ }^{13}$ 27-33 although here it seems that malnutrition may be a contributing factor $^{34}$ in some instances.

Most, though not all, of the nutritional rickets that occurs in the UK is seen in patients of black or Asian origin and it is well recognised that the darker skin colour of these ethnic groups is a contributing factor to the high incidence of nutritional vitamin D deficiency. Darker skinned individuals are just as capable as those with lighter skins of synthesising vitamin $\mathrm{D}$, but require greater exposure to ultraviolet light to do so. ${ }^{3}$ Other factors, such as nutritional deficiency associated with macrobiotic, ${ }^{12} 35$ vegetarian, ${ }^{163637}$ strict vegan, ${ }^{38}$ or "health food" milk alternatives 39 diets, and low exposure to sunlight, either by staying indoors or covering the skin are also important. ${ }^{40}$ Breast milk contains little vitamin D and breast fed infants should receive vitamin D supplements. ${ }^{4}$

Vitamin D deficiency classically presents with symptoms of bony deformity such as bowed legs, swelling of the wrists, a "rickety rosary", and muscle weakness. If the rickets is severe enough, fractures may ensue ${ }^{24} 42$ and may simulate child abuse. ${ }^{43}$ However, a significant proportion of these patients have symptoms of hypocalcaemia which may cause convulsions, stridor, and neuromuscular irritability. ${ }^{33}{ }^{44-46}$ In addition, surveys of at risk populations have shown that a significant proportion have subclinical vitamin D deficiency. ${ }^{47}$ Radiological evidence of rickets is not always present in these patients ${ }^{33} 46$ and this can lead to diagnostic confusion, such as with hypoparathyroidism or pseudohypoparathyroidism, unless the possibility of vitamin D deficiency is considered ${ }^{48}{ }^{49}$ For instance, we describe in this issue 65 cases of vitamin D deficiency in northeast and southeast London. ${ }^{46}$ Forty five per cent $(n=29)$ of these had hypocalcaemic symptoms, of whom 55\% $(n=17)$, more than a quarter of the total, had no radiological evidence of rickets. These patients were all either under the age of 2 years or in adolescence and we speculate that this is because growth is most rapid at these ages when demand for calcium by bone is so high that hypocalcaemia develops before rickets can ensue. Vitamin D deficiency must therefore always be excluded before the cause of hypocalcaemia can be defined.

Treatment of vitamin D deficiency is usually straightforward and consists of oral supplementation with vitamin D. Shaw and $\mathrm{Pal}^{50}$ recommend 3000 units daily for infants under 6 months and 6000 units for older children. We have found that half this dose is sufficient. However, we have also seen a number of infants who have presented with vitamin D deficiency despite being fed with formula milk preparations, which are fortified with vitamin D, or who have been given vitamin supplements in recommended amounts $(400$ units daily). It seems that the mothers of these infants are also vitamin D deficient $^{14165152}$ and that, while 400 units daily of vitamin $\mathrm{D}$ is sufficient to prevent deficiency in replete individuals, this may be insufficient to correct deficiency if this is already present at birth. Nevertheless, oral supplementation with vitamin $\mathrm{D}$ is an effective way 
of both preventing and treating vitamin D deficiency.

An alternative, equally effective, treatment strategy is to use stosstherapy, a single large dose of vitamin D (300000 to 600000 units) as a single dose given either orally or parenterally. ${ }^{53}$ This is particularly useful if there are concerns about compliance with treatment. Alphacalcidol, a synthetic analogue of vitamin D which is converted to 1,25 $(\mathrm{OH})_{2} \mathrm{D}$, has no part to play in the treatment of nutritional vitamin D deficiency as large doses have to be given initially to mimic the supraphysiological rise in $1,25-(\mathrm{OH})_{2} \mathrm{D}$ which occurs naturally at the start of treatment with vitamin D. ${ }^{1354}$ Not only does a poor response often result from the use of "physiological" doses, but it also does not address the underlying issue of vitamin $\mathrm{D}$ deficiency. If hypocalcaemia is the presenting symptom, initial treatment with calcium supplementation, by intravenous infusion if necessary, will be required, and oral calcium supplements in addition to vitamin D increases the rate of recovery. ${ }^{55}$

Nutritional rickets has always been with us but, following the recognition of its principal cause, was largely eradicated in Western society. Large scale immigration from the West Indies and Indian subcontinent resulted in its reappearance, but systematic campaigns of vitamin D supplementation, such as the Glasgow Rickets Campaign of the 1970s, were successful in reducing its incidence. The initial phase of this, a campaign of voluntary free supplementation accompanied by a health education programme aimed mainly at community health workers and the Asian community, ${ }^{56}$ was successful in reducing the number of admissions to hospital with symptoms of vitamin D deficiency, which had been increasing before $1973 .{ }^{57}$ In 1979 an official campaign was launched to supplement all children at risk, and this produced a significant reduction in hospital admissions with rickets. ${ }^{58}$

However, there is now good evidence to suggest that, since such campaigns have been relaxed, a third wave resurgence of vitamin D deficiency is now being seen. ${ }^{59-62}$ Some of this increase may be related to the recognition that vitamin $\mathrm{D}$ deficiency may cause problems other than rickets but it is, nevertheless, a serious indictment of community services that this is happening. Little is known of the long term effects of vitamin D deficiency on bone development, but it is probably one of the factors which contributes to "involutional" osteoporosis in later life..$^{5}$ In addition, vitamin $\mathrm{D}$ deficiency may have an important part to play in other diseases of adults. Since this is a common condition with a high morbidity, it is incumbent on us as paediatricians to try to minimise it as much as possible.

There is good agreement that vitamin $\mathrm{D}$ deficiency can be prevented by dietary supplementation, but there is disagreement about how much should be given to which individuals. The American Association of Pediatrics has recently recommended that a reduced dose of 200 units be given to all infants, children, and adolescents. ${ }^{63}$ In the UK the Department of Health recommends 400 units for pregnant and lactating women, 340 units for infants under 6 months, and 280 units for children under 4 years. No recommendations are given for older children, ${ }^{64}$ but the importance of ensuring that vulnerable groups-that is, infants, young children, and pregnant women from Asian families as well as young AfricanCaribbean children being reared on strict exclusion diets, receive these supplements is stressed. In practice, both of the vitamin preparations that are available free of charge in the UK provide adequate amounts of vitamin $\mathrm{D}$ and can be provided by general practitioners and health visitors. There is probably no place for universal vitamin D supplementation because of the potential dangers of hypercalcaemia in a few individuals.

It seems, therefore, that nutritional rickets is not returning, but has always continued to be with us. It is increasing in frequency again, partly because it is being recognised in its different manifestations but mainly because vitamin D supplementation is no longer regarded as essential for "at risk" individuals. It is almost certainly the case that the clinically apparent cases of vitamin D deficiency represent the "tip of the iceberg". Unfortunately, this is one iceberg which, despite global warming and the attendant increase in sunshine, is not diminishing in size. The time has come to mount a national campaign to promote awareness of the risks of vitamin D deficiency, particularly among susceptible populations in the UK, and to eliminate it as a cause of morbidity.

Arch Dis Child 2004;89:699-701. doi: 10.1136/adc.2003.036780

Correspondence to: Dr J Allgrove, Newham General Hospital, Glen Road, Plaistow, London E13 8RU, UK; jeremy.allgrove@newhamhealth. nhs.uk

\section{REFERENCES}

1 DeLucia MC, Minick ME, Carpenter TO.

Nutritional rickets with normal circulating 25-

hydroxyvitamin $D$ : a call for reexamining the role of dietary calcium intake in North American infants. J Clin Endocrinol Metab 2003;88:3539-45

2 Mughal Z. Rickets in childhood. Semin Musculoskel Radiol 2002:6:183-90.

3 Lo CW, Paris PW, Holick MF. Indian and Pakistani immigrants have the same capacity as Caucasian to produce vitamin $D$ in response to ultraviolet irradiation. Am J Clin Nutr 1986:44:683-5.

4 Lehtonen-Veromaa MK, Mottonen T, Nuotio IO, et al. Vitamin $D$ and attainment of peak bone mass among peripubertal Finnish girls: a 3-y prospective study. Am J Clin Nutr 2002;76: 1446-53.

5 Holick MF. Vitamin D: a millennium perspective. $J$ Cell Biochem 2003;88:296-307.

6 Brunvand L, Quigstad E, Urdal P, et al. Vitamin D deficiency and fetal growth. Early Hum Devel 1996;45:27-33

7 Cone TE Jr. A rachitic infant painted by Burgkmair 136 years before $\mathrm{Dr}$. Whistler described rickets. Clin Pediatr (Phil) 1980;19:194.

8 Berry JL, Davies M, Mee AP. Vitamin D metabolism, rickets, and osteomalacia. Semin Musculoskel Radiol 2002;6:173-82.

9 Belton NR. Rickets - not only the "English disease". Acta Paediatr Scand Suppl 1986;323:68-75.

10 Pal BR, Shaw NJ. Rickets resurgence in the United Kingdom: improving antenatal management in Asians. J Pediatr 2001;139:337-8.

11 Ashraf S, Mughal MZ. The prevalence of rickets among non-Caucasian children. Arch Dis Child 2002;87:263-4.

12 Dagnelie PC, Vergote FJ, van Staveren WA, et al. High prevalence of rickets in infants on macrobiotic diets. Am J Clin Nutr 1990;51:202-8.

13 Garabedian M, Ben-Mekhbi H. Deficiency rickets: the current situation in France and Algeria. Pediatrie 1989;44:259-64.

14 Park W, Paust H, Kaufmann HJ, et al. Osteomalacia of the mother-rickets of the newborn. Eur J Pediatr 1987; 146:292-3.

15 Benichou JJ, Salliere D, Labrune B. Deficiency rickets in an adolescent girl. Arch Fr Pediatr 1985;42:443-5.

16 Hellebostad M, Markestad T, Seeger Halvorsen K. Vitamin D deficiency rickets and vitamin B12 deficiency in vegetarian children. Acta Paediatr Scand 1985:74:191-5.

17 Freycon MT, Pouyau G, Abeille A, et al. Deficiency rickets in older children. Apropos of 2 cases. Pediatrie 1983;38:485-90.

18 Pedersen P, Michaelsen KF, Molgaard C. Children with nutritional rickets referred to hospitals in Copenhagen during a 10-year period. Acta Paediatr 2003;92:87-90

19 Bonet Alcaina M, Lopez Segura N, Besora Anglerill R, et al. Rickets in Asian immigrants during puberty. An Esp Pediatr 2002;57:264-7

20 Lopez Segura N, Bonet Alcaina M, Garcia Algar 0. Rickets in Asian immigrants. An Esp Pediatr 2002;57:227-30.

21 Feldman KW, Marcuse EK, Springer DA Nutritional rickets. Am Fam Physician 1990;42:131 1-18.

22 Kruger DM, Lyne ED, Kleerekoper M. Vitamin D deficiency rickets. A report on three cases. Clin Orthop 1987; 224:277-83.

23 Hayward I, Stein MT, Gibson MI. Nutritional rickets in San Diego. Am J Dis Child 1987;141:1060-2.

24 Jacobsen ST, Hull CK, Crawford AH. Nutritional rickets. J Pediatr Orthop 1986;6:713-16.

25 Haworth JC, Dilling LA. Vitamin-D-deficient rickets in Manitoba, 1972-84. Can Med Assoc J 1986; 134:237-41.

26 Bachrach S, Fisher J, Parks JS. An outbreak of vitamin $D$ deficiency rickets in a susceptible population. Pediatrics 1979;64:871-7

27 Lulseged S. Severe rickets in a children's hospital in Addis Ababa. Ethiop Med J 1990;28:175-81.

28 Elzouki AY, Markestad T, Elgarrah M, et al. Serum concentrations of vitamin D metabolites in rachitic Libyan children. J Pediatr Gastroenterol Nutr 1989:9:507-12.

29 Lubani MM, al-Shab TS, al-Saleh QA, et al. Vitamin-D-deficiency rickets in Kuwait: the prevalence of a preventable disease. Ann Trop Paediatr 1989:9:134-9. 
30 Lawson DE, Cole TJ, Salem SI, et al. Etiology of rickets in Egyptian children. Hum Nutr Clin Nutr 1987:41:199-208.

31 Underwood P, Margetts B. High levels of childhood rickets in rural North Yemen. Soc Sci Med 1987;24:37-41.

32 Karim F, Chowdhury AM, Gani MS. Rapid assessment of the prevalence of lower limb clinical rickets in Bangladesh. Public Health 2003; 117:135-44.

33 Narchi H, El Jamil M, Kulaylat N. Symptomatic rickets in adolescence. Arch Dis Child 2001;84:501-3.

34 Salimpour R. Rickets in Tehran. Study of 200 cases. Arch Dis Child 1975:50:63-6.

35 Edidin DV, Levitsky LL, Schey W, et al. Resurgence of nutritional rickets associated with breastfeeding and special dietary practices. Pediatrics 1980;65:232-5.

36 Dwyer JT, Dietz WH Jr, Hass G, et al. Risk of nutritional rickets among vegetarian children. Am J Dis Child 1979;133:134-40.

37 Doron D, Hershkop K, Granot E. Nutritional deficits resulting from an almond-based infant diet. Clin Nutr 2001;20:259-61.

38 James JA, Clark C, Ward PS. Screening Rastafarian children for nutritional rickets. $B M J$ 1985;290:899-900

39 Carvalho NF, Kenney RD, Carrington PH, et al. Severe nutritional deficiencies in toddlers resulting from health food milk alternatives. Pediatrics 2001;107:E46.

40 Abdullah MA, Salhi HS, Bakry LA, et al. Adolescent rickets in Saudi Arabia: a rich and sunny country. J Pediatr Endocrinol Metab 2002;15:1017-25.

41 Reeve LE, Chesney RW, Deluca HF. Vitamin D of human milk: identification of biologically active forms. Am J Clin Nutr 1982;36:122-6.
42 Al-Jurayyan NA, El-Desouki ME, Al-Herbish AS, et al. Nutritional rickets and osteomalacia in school children and adolescents. Saudi Med J 2002;23:182-5.

43 Paterson CR. Vitamin D deficiency rickets simulating child abuse. J Pediatr Orthop 1981;1:423-5.

44 Bonnici F. Functional hypoparathyroidism in infantile hypocalcaemic stage I vitamin D deficiency rickets. S Afr Med J 1978:54:611-12.

45 Frontera Izquierdo P. Rickets and tetany in the Spanish bibliography of the nineteenth century. An Esp Pediatr 1975;8:325-30.

46 Ladhani S, Srinivasan L, Buchanan C, et al. Presentation of vitamin D deficiency. Arch Dis Child 2004;89:781-4

47 Abdul-Motaal A, Gettinby G, Mclntosh WB, et al. Relationships between radiological and biochemical evidence of rickets in Asian schoolchildren. Postgrad Med J 1985;61:307-12.

48 Singh J, Moghal N, Pearce SH, et al. The investigation of hypocalcaemia and rickets. Arch Dis Child 2003:88:403-7.

49 Srivastava T, Alon US. Stage I vitamin Ddeficiency rickets mimicking pseudohypoparathyroidism type II. Clin Pediatr (Phil) 2002:41:263-8.

50 Shaw NJ, Pal BR. Vitamin D deficiency in UK Asian families: activating a new concern. Arch Dis Child 2002;86:147-9.

51 Elidrissy AT, Sedrani SH, Lawson DE. Vitamin D deficiency in mothers of rachitic infants. Calcif Tissue Int 1984;36:266-8.

52 Nozza JM, Rodda CP. Vitamin D deficiency in mothers of infants with rickets. Med J Aust 2001; 175:253-5

53 Stogmann W, Sacher M, Blumel P, et al. Vitamin $D$ deficiency rickets: single-dose therapy versus

\section{Substance abuse by children and young people \\ P McArdle}

\section{A contemporary disease}

U se of illicit substances by significant numbers of young people has been of concern for at least a generation in Western Europe and North America. ${ }^{1}$ This is reflected in official statistics, police sources and surveys, and particularly school based anonymous self-reports that have shown a substantial increase in consumption over that time with a further surge during the 1990s. ${ }^{1}$ In addition, the rates of substance use (alcohol and drugs) in the UK currently outstrip those reported elsewhere in Europe. ${ }^{2}$ Furthermore, there is now evidence of illicit substance use by significant numbers of pre-adolescent UK children; ${ }^{3}$ up to $5 \%$ of preteens currently report use of illicit substances and an appreciable number hard drugs such as heroin; apparently an entirely new development.
Despite this exposure to toxic substances, children and young people are not referred in large numbers to health services as a consequence primarily of substance related disorders. In part this is because they present in other ways: through intoxication, accidental or violent injury, self-harm, sexually transmitted disease, teenage pregnancy, and psychiatric disorder. It may be too that traditional services are unprepared for them or for adapting existing skills and resources to attempt to recognise or meet their needs.

A further problem concerns confusion of concepts and terminology. For instance, the WHO has identified "disorders due to psychoactive substance

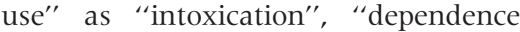
syndrome", and "harmful use". However, because they are in general likely to have been using substances for continuous therapy. Padiatr Padol 1985;20:385-92.

54 Markestad T, Halvorsen S, Halvorsen KS, et al. Plasma concentrations of vitamin D metabolites before and during treatment of vitamin $D$ deficiency rickets in children. Acta Paediatr Scand 1984;73:225-31.

55 Kutluk G, Cetinkaya F, Basak M. Comparisons of oral calcium, high dose vitamin $D$ and a combination of these in the treatment of nutritional rickets in children. J Trop Pediatr 2002;48:351-3.

56 Dunnigan MG, Mclntosh WB, Sutherland GR et al. Policy for prevention of Asian rickets in Britain: a preliminary assessment of the Glasgow rickets campaign. BMJ 1981;282:357-60.

57 Goel KM, Sweet EM, Campbell S, et al. Reduced prevalence of rickets in Asian children in Glasgow. Lancet 1981;2:405-7.

58 Dunnigan MG, Glekin BM, Henderson JB, et al. Prevention of rickets in Asian children: assessment of the Glasgow campaign. BMJ 1985:291:239-42

59 McCaffree J. Rickets on the rise. J Am Diet Assoc 2001;101:16-17.

60 Rowe PM. Why is rickets resurgent in the USA? Lancet 2001;357:1100.

61 Abrams SA Nutritional rickets: an old disease returns. Nutr Rev 2002;60:111-15.

62 Chesney RW. Rickets: the third wave. Clin Pediatr (Phil) 2002;41:137-9.

63 Gartner LM, Greer FR. Prevention of rickets and vitamin $D$ deficiency: new guidelines for vitamin $D$ intake. Pediatrics 2003;111:908-10.

64 Subgroup on Bone Health, Department of Health Working Group on the Nutritional Status of the Population of the Committee on Medical Aspects of Food and Nutrition Policy. Nutrition and bone health: with particular reference to calcium and vitamin D. London: HMSO, 1998.

a relatively short time, dependence among young people is probably less common than among adults. Also, the definition of "harmful use" specifically excludes "socially negative consequences", an important type of harm for developing children and youth. DSM IV, the classification system of the American Psychiatric Association, describes a range of "substance related disorders", including "substance use disorders", of which "substance abuse" is a subcategory. This is characterised by "a maladaptive pattern of substance use manifested by recurrent and significant adverse consequences related to the repeated use of substances". This includes:

"... failure to fulfil major role obligations at work, school or home ... recurrent ... legal problems (and) repeated substance use despite having persistent or recurrent social or interpersonal problems caused or exacerbated by the effects of the substance ..."

In addition, a large US survey ${ }^{4}$ has reported that among 15-16 year olds who had used illicit drugs more than five times ("... two thirds of those who had ever used"), almost $80 \%$ of boys and $70 \%$ of girls had been "drugged or high" at school and over half had been 
so while engaged in sports. The authors used the term "problem use" for this behaviour which is "intrinsically problematic from a developmental perspective". This is consistent with UK data from older adolescents and young adults among whom $40 \%$ of those who acknowledged drug use in the past year reported dependence. ${ }^{5}$ Hence, the widespread view that much drug use by youth is experimental or to be regarded as part of a normal social repertoire ${ }^{6}$ is probably misleading.

The Health Advisory Service ${ }^{7}$ further discussed distinctions between use and "misuse", the latter incorporating "problem use"; and pointed out that "use" may be best confined to "use of alcohol safely (and) ... experimental use" of illicit drugs in the older adolescent. A cautious view may be that any use of illicit substances, and perhaps alcohol without adult sanction, in younger adolescents or children is potentially problematic and should be referred to as "misuse" which therefore includes substance use disorders, abuse, and problem use.

Cannabis is the most widely misused illicit substance by Western youth. ${ }^{2}{ }^{3}$ It may be more potent than in the past and is currently often consumed in very high daily doses. ${ }^{8}$ Consequently, cannabis can potentially lead to dependence, ${ }^{9}$ the use of other substances, ${ }^{10}$ and physical consequences. ${ }^{11}$ In the short term, perhaps as long as 30 days postconsumption, there is evidence of dose related impaired cognitive performance, particularly evident among the less intellectually advantaged.${ }^{12}$ In the longer term there is accumulating evidence of a dose related risk of schizophrenia that among drugs of abuse may be specific to cannabis. ${ }^{13}$

Other health related consequences of substance misuse include sexual disinhibition and teenage pregnancy, ${ }^{14}$ deliberate self harm (by $5-10 \%$ of boys and approximately $25 \%$ of girls who "use drugs" or drink heavily ${ }^{15}$ ) and death. ${ }^{16}$ UK Office of National Statistics data reveal that suicide, which shows a strong link with substance abuse, ${ }^{17}$ is second only to accidents as a cause of death among 15-24 year old males. Even among females, it is the third most common cause of death in this age group behind accidents and cancer. Deaths in young people directly attributable to substance misuse far outstrip, for instance, deaths linked to asthma. Among accommodated children, substance misuse may be a more common cause of death than mistreatment. ${ }^{18}$ Hence, health services for children and young people should have a much greater capacity to identify, assess, and respond effectively to substance misuse than is currently the case. ${ }^{19}$ Potentially, this is not just a question of new specialists but, in order to reflect more closely the evolving patterns and scale of pathology particularly in regard to adolescents, of a reorientation of the entire child health sector, and of the research and training of its personnel.

Substance misuse has complex roots: in biological predisposition, personal development, and social context. At least in outline, the latter has been recognised for some time; as Court $^{20}$ remarked:

\section{"many of those ... misusing drugs are young people with ... emotional deprivation, disturbance and separation in the family and some- times institutionalism".}

More specific social correlates include parent-child conflict, child physical and sexual abuse, ${ }^{21} 22$ family breakdown, ${ }^{23}$ and in relation to school, scholastic failure and estrangement from teachers. ${ }^{1}$ These experiences are linked with lasting distress ${ }^{24}$ and can interfere with trusting and supportive attachments to adults. They also predict affiliation with networks of deviant peers $^{25}$ who introduce them to and supply them with illicit substances. This is not the same as "peer pressure" but describes a developmental trajectory that is said to "shape" a child's social development towards deviant peers and to distance them from adults. Similar issues arise for youth who are identifiable administratively (homeless youth, those accommodated by the local authority, or involved with crime) rather than clinically as at high risk of substance abuse. ${ }^{26}$

A complementary viewpoint emerges from consideration of the links between substance abuse and conduct problems or disorder, "a repetitive and persistent pattern of dissocial, aggressive, or defiant conduct". Conduct problems have been subclassified as "adolescent limited" and "life-span persistent". ${ }^{27}$ If "life-span persistent" or early onset, disturbed behaviour may be apparent from preschool years, linked with a range of neurodevelopmental vulnerabilities, learning disabilities, impairments in capacity to form social relationships and perhaps in motor development, as well as symptoms of attention deficit hyperactivity disorder ${ }^{28}$ that are likely to be substantially genetic. ${ }^{29}$ In keeping with often difficult lives, many of these children experience considerable suffering manifest in anxiety and depressive symptoms. ${ }^{30}$ It is likely that most children referred to paediatricians with more severe behaviour problems fall into this early onset group. The combination of this type of individual vulnerability, other psychosocial adversity, association with deviant peers, and high availability of drugs virtually ensures substance use and presents a potent risk for abuse. However, this risk may be reduced by appropriate early intervention including, where appropriate, stimulant medication as part of a package of interventions.

Substance misuse in young adolescents or pre-adolescents may in itself indicate care and development that is awry and may require child protection investigation. Particularly among younger adolescents and children, developmentally inappropriate use of terms such as "empowerment" or "choice" should not mislead clinicians into accepting at face value refusal of treatment, undertaking to offer complete confidentiality, or to exclude parents and carers. Indeed, involvement of the latter may be crucial for successful intervention and a strong wish to exclude parents may be itself a matter of concern and raise questions concerning significant harm. ${ }^{7}$ Hence, substance misuse often represents a further layer on pre-existing complex developmental and social adversity, much of it familiar to child specialists. Indeed, until proven otherwise, any young person presenting with substance misuse (including intoxication) has a range of other problems.

Professionals trained to work with children potentially bring invaluable existing generic as well as specialist skills and knowledge to the health care response to substance misuse. However, they may need to embrace

\section{"a broader view of health-empha- sising mental and social as well as physical ... well-being as well as the absence of problems ...". ${ }^{31}$}

To intervene effectively does not necessarily require elaborate new skills or retraining, but often requires thoughtful adaptation of existing skills; structured opportunities for reflection, familiarisation, and initially supervised practice, depending on the degree of special interest. Currently, training at different levels is under development by the National Treatment Agency and UK Royal Colleges. ${ }^{32}$

A view of competence that may be appropriate for all doctors who regularly treat older children or adolescents envisages adequate history taking, accurate information and advice, and appropriate referral. An adequate history encompasses details not only of the presenting complaint and exploration of substances used but also of the developmental and environmental, including educational 
and social context of the individual. This form of systems review should seek to establish: some degree of rapport with a perhaps sceptical, mistrustful young person; who is caring for them and whether that person is able to function as a parent; whether the local authority is discharging its responsibility to educate them; whether there is evidence of child abuse, developmental problems, or mental disturbance; and who their peers are. In addition, details of their consumption of substances need to be elicited, confirmed if possible by hair, saliva, or urinalysis. In particular, is there evidence of dependence or particular risk through pregnancy or parenteral administration? If these data are gathered, it is likely that for many it will be the first time that anyone has asked. Furthermore, they present a framework for further action and advocacy for the patient's wellbeing. ${ }^{33}$

Even brief interventions that are characterised by a good assessment, accurate information, and advice to reduce consumption, probably in the context of good rapport rather than a lecture, can be surprisingly effective in reduction of substance misuse by adults. ${ }^{34}{ }^{35}$ Modified by additional involvement of parents and pointers to relevant local statutory and voluntary agencies, this approach could form the basis of a good consultation at this level. It might be particularly relevant to, for instance, general practice, community paediatrics, and accident and emergency departments.

At a second level of expertise, suggesting an interest in adolescent medicine, there may be scope for more elaborate intervention. This might involve energetic and sustained attention to engaging and working with young people and families and to liaison with or mobilisation of other agencies (for example, schools, child protection or family support agencies, juvenile justice) to reduce harm, and promote good care, normal development, and health. ${ }^{36}$ Evidence from recent trials ${ }^{37}$ suggests that such a package can ameliorate substance misuse and associated comorbidity. Even retaining young people in contact with services may be helpful, perhaps by being on hand when a therapeutic opportunity arises, or through reducing isolation or desperation.

It may also be necessary to facilitate withdrawal from addictive drugs and in a small number to prescribe substitute agents, ${ }^{38}$ bearing in mind that doctors are responsible for "good clinical care" "s9 $^{\text {"39 }}$ and should never be persuaded to become a mere prescribing service. The narrow therapeutic index of some of the available agents might point to such a provision beginning as a joint consulta- tion with an adult addictions service, perhaps with a view to the emergence of a specialist level of expertise, "paediatric addiction medicine". ${ }^{40}$ It is not suggested that large numbers of such specialists are likely to emerge. However, sessional commitments and leadership from interested paediatricians, in partnership with others including child psychiatrists, would undoubtedly enrich the competence and rigour in the field as a whole and raise standards of care.

For the moment, substance misuse and its associated morbidity remain unfamiliar to many health practitioners who may be tempted to view it as (merely) a social problem. It is true that substance misuse is determined by cultural, social, as well as intrinsic factors (including personal choice) and it is common. Nevertheless, this is also true of many familiar health problems that in earlier generations have established themselves as unequivocally the business of health services. Indeed, it may be possible to argue that substance use disorder should be regarded as a contemporary disease of youth. This is not unnecessary "medicalising" but a call for medical professionals to be conceptually somewhat less exclusively and in a narrow sense, "bio-", and more holistically "medical", and to engage with the sometimes fatal predicament of a great number of young people in difficulties in our own cities and neighbourhoods. It is also an entreaty to research funders to invest in ways that are maximally relevant to youth. Finally, substance misuse presents an opportunity: for medicine and other health care professions to demonstrate that they remain interested in, relevant to, and competent for the health needs of modern youth.

\section{Arch Dis Child 2004:89:701-704.} doi: 10.1136/adc.2003.040584

Correspondence to: Dr P McArdle, Consultant Child and Adolescent Psychiatrist and Senior Lecturer, Fleming Nuffield Unit, Newcastle, North Tyneside and Northumberland Mental Health Trust, Burdon Terrace, Newcastle upon Tyne NE2 3AE, UK; mcardlep@aol.com

\section{REFERENCES}

1 Frischer M, McArdle P, Crome I. The epidemiology of substance misuse in young people. In: Crome I, Ghodse H, Gilvarry E, McArdle P. Substance misuse and young people. London: Gaskell, 2003

2 Hibbell B, Anderson B, Bjamason T. Alcohol and other drug use among students in 30 European countries - the 1999 ESPAD Report. Stockholm: Council for Information on Alcohol and Other Drugs, Council of Europe, Pompidou Group, 1999.

3 McKeganey N, Mclntosh J, MacDonald F, et al. Preteens and illegal drugs: use, offers, exposure and prevention Home Office. In press.

4 Zoccolillo M, Vitaro F, Tremblay RE. Problem drug and alcohol use in a community sample of adolescents. J Am Acad Child Adolesc Psychiatry 1999;38:900-7.

5 Farrell $M$, Howes $S$, Bebbington $P$, et al. Nicotine, alcohol and drug dependence and psychiatric comorbidity. Results of a national household survey. Br J Psychiatry 2001;179:432-7.

6 Parker H, Aldridge J Measham F. Illegal leisure: the normalisation of adolescent recreational drug use. London: Routledge, 1998.

7 Gilvarry E, Christian J, Crome I, et al. The substance of young needs review. London: Health Advisory Service, 2001

8 Ashton H. Cannabis or health? Curr Opin Psychiatry 2002;15:247-53.

9 Fergusson D, Horwood L. Cannabis use and dependence in a New Zealand birth cohort. N Z Med J 2000;1 13:56-8.

10 Fergusson D, Horwood L. Does cannabis use encourage other forms of illicit drug use? Addiction 2000;95:505-20.

11 Taylor D, Poulton R, Moffitt T, et al. The respiratory effects of cannabis dependence in young adults. Addiction 2000;95:1669-77.

12 Bolla K, Brown K, Eldreth D, et al. Dose-related neurocognitive effects of marijuana use. Neurology 2002;59:1337-43.

13 Zammit S, Allebeck P, Andreasson S, et al. Self reported cannabis use as a risk factor for schizophrenia in Swedish conscripts of 1969: historical cohort study. BMJ 2002;325:1 199.

14 Ramrakha S, Caspi A, Dickson N, et al. Psychiatric disorders and risky sex in young adulthood: a cross sectional study in a birth cohort. BMJ 2002;321:263-6.

15 Hawton K, Rodham K, Evans E. Deliberate self harm in adolescents: self report survey in schools in England. BMJ 2002;325:1207-1 1 .

16 Schifano F, Oyefeso A, Webb L, et al. Review of deaths related to taking ecstasy, England and Wales, 1997-2000. BMJ 2003;326:80-1.

17 Gould M, Fisher P, Parides M, et al. Psychosocial risk factors of child and adolescent completed suicide. Arch Gen Psychiatry 1996;53:1155-62.

18 Kalland M, Pensola T, Merilainen J, et al. Mortality in children registered in the Finnish child welfare registry: population based study. $B M$ 2001;323:207-8.

19 Bennett D, Bauman A. Adolescent mental health and risky sexual behaviour: young people need health care that covers psychological, sexual, and social areas. BMJ 2000;321:251-2.

20 Court SDM. Fit for the future. Report of the Committee on Child Health Services. London: HMSO, 1976.

21 Diaz A, Simantov E, Rickert VI. Effect of abuse on health: results of a national survey. Arch Pediatr Adolesc Med 2002;156:81 1-17.

22 Molnar B, Buka S, Kessler R. Child sexual abuse and subsequent psychopathology: results from the National Comorbidity Survey. Am J Public Health 2001;91:753-60.

23 McArdle P, Wiegersma A, Gilvarry E, et al. Family structure and function and youth drug use. Addiction 2002;97:329-36.

24 Woodward L, Fergusson D. Life course outcomes of young people with anxiety disorders in adolescence. J Am Acad Child Adolesc Psychiatry 2001;40:1086-93.

25 Fergusson D, Horwood L. Prospective childhood predictors of deviant peer affiliations in adolescence. J Child Psychol Psychiatry 1999:40:581-92

26 Greene J, Ennett S, Ringwalt C. Substance abuse among runaway and homeless youth in three national samples. Am J Public Health 1997;87:229-35.

27 Moffitt $\mathrm{T}$, Caspi A, Harrington $\mathrm{H}$ et al. Males on the life-course-persistent and adolescence-limited antisocial pathways: follow-up at age 26 years Dev Psychopathol 2002;14:179-207.

28 Mannuzza S, Gittelman Klein R, Bonagura N, et al. Hyperactive boys almost grown up. V. Replication of psychiatric status. Arch Gen Psychiatry 1991;48:77-83.

29 Thapar A, Harrington R McGuffin P. Examining the comorbidity of ADHD-related behaviours and conduct problems using a twin study design. Br J Psychiatry 2001; 179:224-9.

30 Boys A, Farrell M, Taylor C, et al. Psychiatric morbidity and substance use in young people 
aged 13-15 years: results from the Child and Adolescent Survey of Mental Health. Br J Psychiatry 2003;182:509-17.

31 US Congress, Office of Technology Assessment Adolescent health. Volume 1: summary and policy option OTA-H-468. Washington, DC: US Government Printing Office, April 1991.

32 Emminson M. Paper presented to joint meeting of faculties of substance misuse and child and adolescent psychiatry, 2003.

33 Riggs P, Davies R. A clinical approach to integrating treatment for adolescent depression and substance abuse. J Am Acad Child Adolesc Psychiatry 2002;41:1253-5.
34 Heather N. Effectiveness of brief interventions proved beyond reasonable doubt. Addiction 2002;97:293-4

35 Samet J, Rollnick S, Barnes H. Beyond CAGE: a brief clinical approach after detection of substance abuse. Arch Intern Med 1996; 156:2287-93

36 American Academy of Pediatrics, Committee on Substance Abuse. Tobacco, alcohol, and other drugs: the role of the pediatrician in prevention and management of substance abuse. Pediatrics 1998;101(1 pt 1):125-8.

37 Liddle H, Dakof G, Parker K, et al. Multidimensional family therapy for adolescent drug abuse: results of a randomized clinical trial. Am J Drug Alcohol Abuse 2001:27:651-88.

38 Kosten T, O'Connor PG. Management of drug and alcohol withdrawal. N Engl J Med 2003;348: 1786-95.

39 General Medical Council. Good medical practice. London: GMC, 1998.

40 American Academy of Pediatrics, Committee on Child Health Financing and Committee on Substance Abuse. Improving substance abuse prevention, assessment, and treatment financing for children and adolescents. Pediatrics 2001;108:1025-9.

\section{IMAGES IN PAEDIATRICS}

\section{Crossed fused ectopic left kidney}

A 5 year old boy was referred to our paediatric ward with fever, headache, and vomiting. Clinical examination elicited tenderness over both flanks and a renal ultrasound was performed. A mass extending over the midline compatible with the diagnosis of a crossed fused ectopic left kidney was noted (arrows, fig 1). A technetium-DMSA scan revealed a normally located and sized right kidney with small horizontal left kidney connected to its lower pole (arrows, fig 2). Renal SPECT showed absorption of $20 \%$ in the right and $5 \%$ in the left kidney.

A crossed fused renal ectopia is an entity where one kidney crosses over to the other side and the parenchyma of the two kidneys fuse. In most cases it involves the left kidney, as in our patient. Renal function is usually normal. Other anomalies associated with this condition are the VACTER syndrome, hydronephrosis, annular pan-

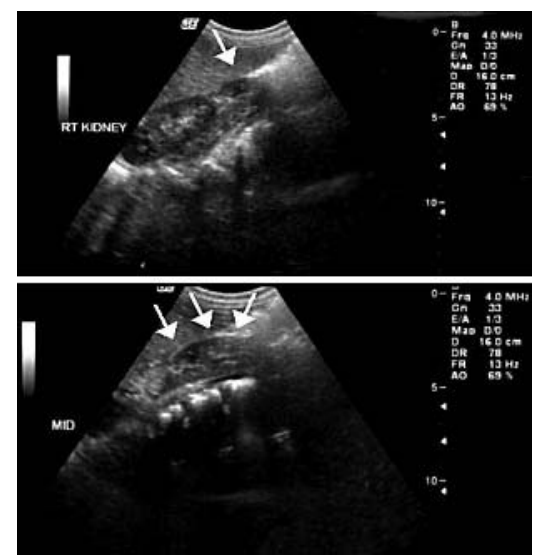

Figure 1 Renal ultrasound showed a mass extending over the midline compatible with the diagnosis of a crossed fused ectopic left kidney.

creas, and multicystic dysplasia. Most cases are sporadic but dominant inheritance has been reported.

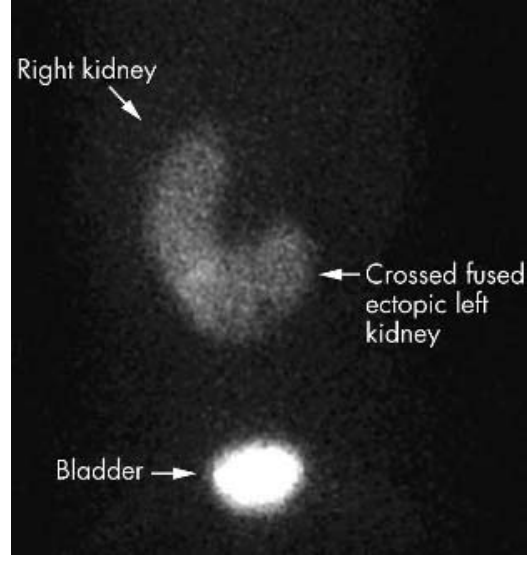

Figure 2 On the lower pole of a normal right kidney, there is a texture adjacent to it extending beyond the midline and suspected as an ectopic left kidney.

O Hochwald, R Shaoul Paediatric Department, Bnai Zion Medical Center, Haifa, Israel; orinoam@zahav.net.il

Accepted 5 December 2003

\section{Acknowledgement}

We would like to thank Dr S A Loria for providing us with the 1970-2000 issues of Archives of Disease in Childhood, allowing us to post them online as part of our digitising project. 